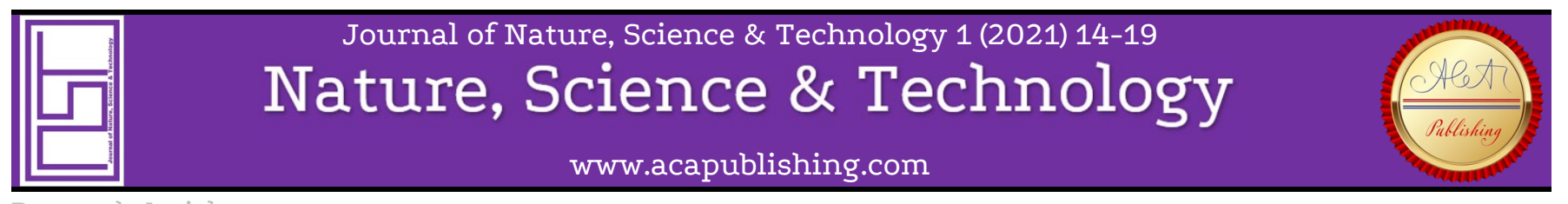

Research Article

\title{
Thermal Performance of Thermosyphons Intended for Evacuated Tube Solar Collector Using Graphene Oxide Nanofluids
}

\author{
P.L.O. Machado, G.A. Bartmeyer, V.V. Dimbarre, R.O. Souza, V.M. Lenart, R.F.T. Gomez, P.H.D. Santos, T. \\ Antonini Alves* \\ Federal University of Technology - Parana (UTFPR), Brazil
}

\section{Keywords}

Thermosyphons,

Heat pipes,

Solar Collectors,

Nanofluids,

Graphene oxide.

\begin{abstract}
Vacuum tube solar collectors are composed by two concentric glass tubes with the annular space evacuated. At the inner tube a thermosyphon is placed inside a metallic fin in order to absorb sun's irradiation and heat running water placed at a manifold. Thermosyphons are passive heat transfer devices that absorb heat at the evaporator region, evaporating the working fluid that reaches the condenser in the form of steam. At the condenser, heat is dissipated to the environment, condensing the working fluid that returns to the evaporator, closing the thermodynamic cycle. In this study, thermosyphons with three different working fluids (5 and 10\% graphene oxide nanofluids and distilled water) were built and experimentally tested. The evaporator and the adiabatic section have an outer diameter of $8.33 \mathrm{~mm}$ and lengths of $1,600 \mathrm{~mm}$ and $40 \mathrm{~mm}$, respectively. The condenser has an outer diameter of $13.40 \mathrm{~mm}$ and a length of $35 \mathrm{~mm}$. The filling ratio used was $50 \%$ of the evaporator's volume. A resistive tape wrapped at the evaporator and connected to a power supply was responsible for heating the working fluid by Joule effect, and water flow rates of $0.50,0.75$, and $1.00 \mathrm{~L} / \mathrm{min}$ were responsible for condensing the working fluid at the condenser. Heat loads of 35,55 , and $75 \mathrm{~W}$ were applied to the devices and $\mathrm{K}$-type thermocouples were responsible for acquiring temperature data from the thermosyphons, allowing the thermal analysis based in the temperature distribution and thermal resistance for each working fluid. The best working fluid for the conditions proposed, out of the three investigated, was $5 \%$ graphene oxide.
\end{abstract}

\section{Introduction}

Solar energy is one of the most widely available form of renewable energy, theoretically having the capacity to fully meet the global energy demand [1]. In spite of this, the entire world relies on fossil fuels to fulfil over $80 \%$ of the current energy needs, indicating that the technologies used to harvest solar energy require improvements and new investigations [2].

Solar energy can be used to generate electricity from photovoltaic panels or thermal heating in solar collectors [3]. Among solar collectors, evacuated tube solar collectors (ETSC), or vacuum tube solar collectors, are characterized by concentric glass tubes in which the annular space is evacuated. At the inner glass tube there is an absorber plate (metal fin) in which the thermosyphon or the heat pipe is located. The solar irradiation falls upon the glass tube and is transformed into heat in the absorber plate. This heat is then transferred to the thermosyphon, which will then exchange that heat by running water over the condenser. Both running water and the condenser region are inserted in a heat exchanger called manifold, which is isolated from the environment. The interior of the tubes can be seen at Figure 1.

Both a thermosyphon and a heat pipe consist of evacuated metal tubes filled with a certain amount of working fluid, which can exchange high heat rates over long distances with a low temperature gradient, since they operate from the latent heat of vaporization of the working fluid. The main difference between a thermosiphon and a heat pipe is the fact that the heat pipe has a porous structure on the pipe walls, whether it is a metallic mesh, sintered material or grooves, which are then responsible for the movement of the fluid. In the thermosyphon, this fluid transport occurs by pressure gradients and the action of gravity $[4,5]$

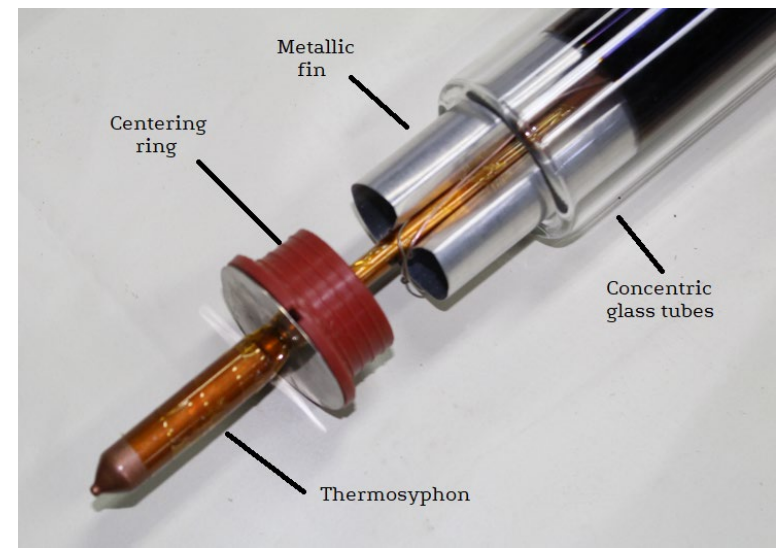

Figure 1. ETSC tube

They consist basically in an evacuated metallic tube filled with a working fluid and have three main regions with different functions: evaporator, adiabatic section, and condenser [5], as it can be seen at Figure 2.

The lower region of the tube is called evaporator, the region that contains the working fluid and in which heat is absorbed from a hot source. When absorbing heat, the working fluid starts an evaporation process, a process that occurs at low temperatures because the interior of the tube is evacuated. The fluid vapor is then transported through the center of the tube due to pressure gradients, reaching the upper region called the condenser [7]. 


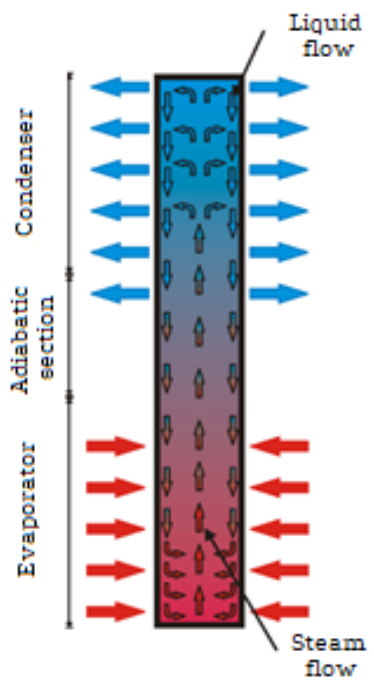

Figure 2. Schematic diagram of a thermosyphon [6]

In the condenser, the heat absorbed in the evaporator and transported by the steam is dissipated to the external environment, causing the condensation of this steam. When condensing, due to the action of gravity, the working fluid in liquid form flows through the walls of the tube, returning to the evaporator region, completing the thermodynamic cycle [8].

The adiabatic section is located between the evaporator and the condenser. In this section, there is no heat transfer between the thermosyphon and the environment. In some cases, the adiabatic section is absent [9].

The thermo physical properties of the working fluid are directly related to the performance of a thermosyphon. Vapor pressure, stability, toxicity, thermal conductivity, chemical compatibility between the working fluid and the tube casing material must be taken into account, and the operating temperature range is one of the first considerations that must be made when choosing the working fluid $[5,10,11]$.

The influence of the working fluid on ETSC has been investigated in [10], in which hexane, petroleum ether, chloroform, acetone, methanol, and ethanol are used and [12], where water and ethanol were compared. Nanofluids (base fluids added with nanoparticles) were also investigated, such as [13] and [14], which used MgO and multi-walled carbon nanotubes (MWCNT)/ water nanofluids as working fluids, respectively.

Taking that into account, this present study intends to perform an experimental investigation of the influence of the thermosyphon's working fluid on the thermal performance of a high pressure vacuum tube solar collector. For this, three different thermosyphons were manufactured, tested and compared, using distilled water, 5\% graphene oxide and, $10 \%$ graphene oxide nanofluids as working fluids.

\section{Methodology}

This section presents the apparatus and proceedings used in order to achieve the main goal of this work.

\subsection{Experimental apparatus}

The experimental apparatus used in this study is shown in Fig. 3 and was composed of a Politerm ${ }^{\mathrm{TM}} 16 \mathrm{E}$ power supply, an Agilent ${ }^{\mathrm{TM}} 34970 \mathrm{~A}$ data acquisition system with an Agilent ${ }^{\mathrm{TM}}$ 34901A 20-channel multiplexer, a Solab ${ }^{\mathrm{TM}}$ SL-130 ultra-thermostatic bath, a Dell ${ }^{\mathrm{TM}}$ laptop, a UPS NHS ${ }^{\mathrm{TM}}$ and an Omega Engineering ${ }^{\mathrm{TM}}$ FL-2051 variable area flowmeter with regulating valve.

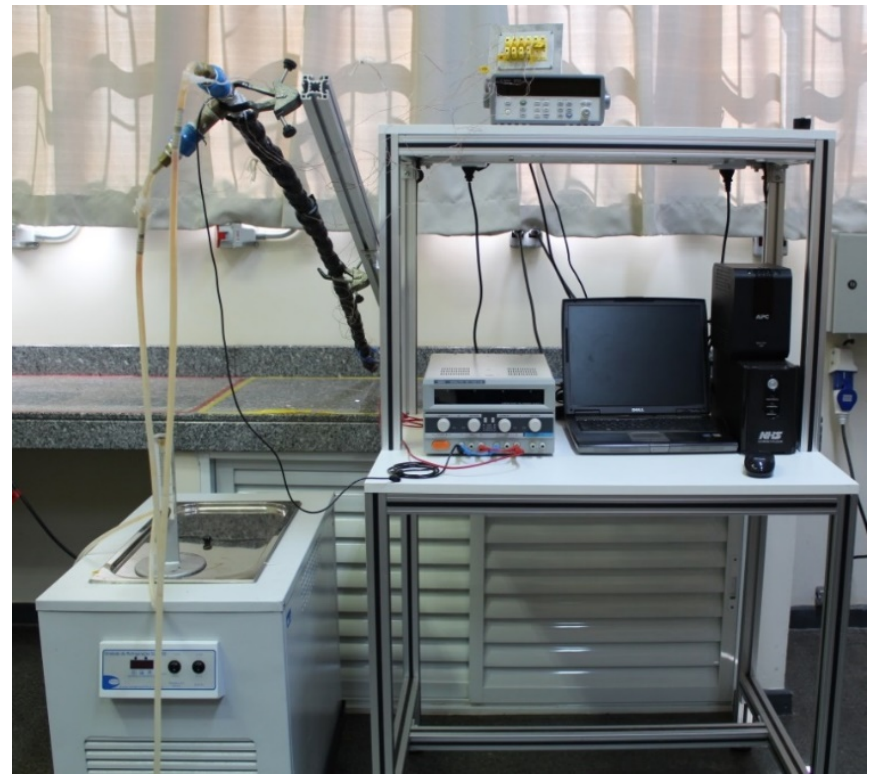

Figure 3. Experimental apparatus

The total length of the evaporator and the adiabatic section was covered with a Kapton ${ }^{\mathrm{TM}}$ tape. A total of eight K-type Omega Engineering $^{\mathrm{TM}}$ thermocouples were responsible for acquiring temperature data from the thermosyphon, six equally spaced at the evaporator, one at the adiabatic section, and one thermocouple at the condenser.

A resistive tape was wrapped around the entire length of the evaporator and connected to the power supply. The condenser was inserted into a $50 \mathrm{~mm}$ diameter PVC tee. Through connections and hoses, the tee was connected to the ultra-thermostated bath, simulating the fluid flow in a manifold. Data of inlet and outlet water temperature at the tee were collected by thermocouples.

The entire length of the evaporator and adiabatic region was isolated from the external environment with aeronautical thermal insulation and a polyethylene layer.

\subsection{Experimental procedure}

The thermosyphons were manufactured from a copper ASTM B75 tube with a total length of $1,675 \mathrm{~mm}$. The evaporator and the adiabatic section have an outer diameter of $8.33 \mathrm{~mm}$ and lengths of $1,600 \mathrm{~mm}$ and $40 \mathrm{~mm}$, respectively. The condenser has an outer diameter of $13.40 \mathrm{~mm}$ and a length of $35 \mathrm{~mm}$. A total of three thermosyphons were made, each one filled with a different working fluid: $5 \%$ graphene oxide nanofluid, $10 \%$ graphene oxide nanofluid, and distilled water. To obtain graphene oxide, the Hummers' Method was used, in which graphite is subjected to a chemical reaction with sulfuric acid, using potassium permanganate as catalysts $[15,16]$. The filling ratio (ratio between working fluid's volume and evaporator's volume) for the thermosyphons was 50\%. The methodology used in the manufacturing of the thermosyphons (preparation, cleaning, assembly, tightness test, evacuation procedure, and filling with working fluid) was based on the information provided in [17].

All the parts of the thermosyphon were first cleaned using water and soup, followed by acetone and sulfuric acid. For the assembly, the tin brazing process was used. After assembly, air was pumped into the device while it was submerged in a container filled with water, in order to perform the tightness test. After that, the device was evacuated using a vacuum pump and filled using a burette. The construction of the thermosyphon is presented in greater detail in [18].

For the experimental tests, the evaporator was heated by the Joule effect due to the power dissipation on the resistive tape wrapped in this section, causing the evaporation of working fluid. A water flow of 
$0.50,0.75$, and $1.00 \mathrm{~L} / \mathrm{min}$ in the condenser was responsible for the condensation of the steam, closing the thermodynamic cycle. Tests were carried out for a heat load of 35,55 , and $75 \mathrm{~W}$ in a position at $25^{\circ}$ from the horizontal (evaporator below condenser) corresponding to the latitude of the city of Ponta Grossa/PR/Brazil: 25॰05'42" South. The water used for the cooling process and the ambient temperature were kept at $18.0^{\circ} \mathrm{C} \pm 0.5^{\circ} \mathrm{C}$ by the ultra-thermostatic bath and a Carrier ${ }^{\mathrm{TM}}$ air conditioning system, respectively.

The thermal analysis was performed based on the average temperatures of the three sections of the thermosyphon for each heat load dissipated. From these values, it was possible to determine the thermal resistance $\left(R_{t h}\right)$. The thermal resistance can be calculated by Equation (1), in which $T_{\text {cond }}$ and $T_{\text {evap }}$ represent the average temperatures in the condenser and evaporator, respectively, and $q$ represents the thermal load applied to the thermosyphon in question.

$R_{\text {th }}=\frac{\left(T_{\text {evap }}-T_{\text {cond }}\right)}{q}$

In the case of the analysis of uncertainties, results of experimental measurements must carry a measurement uncertainty. The analysis of this uncertainty is necessary to estimate the degree of doubt associated with the measurement result. To perform the uncertainty analysis, the uncertainty method described by [19] was used. With the principle of combining uncertainty of related magnitude, the Engineering Equation Solver ${ }^{\mathrm{TM}}\left(\mathrm{EES}^{\mathrm{TM}}\right)$ software was used to propagate the uncertainties. The uncertainty $\Delta R$ of a result $R=f\left(x_{1}, x_{2}, \ldots, x_{n}\right)$ with measures at $x_{1}, \ldots, x_{n}$ is expressed by Equation (2) [20].

$$
\Delta R=\sqrt{\left(\frac{\partial R}{\partial x_{1}} \partial x_{1}\right)^{2}+\ldots+\left(\frac{\partial R}{\partial x_{n}} \partial x_{n}\right)^{2}}
$$

The experimental uncertainties involved in this study are presented in detail in Table 1.

Table 1. Experimental uncertainties

\begin{tabular}{cc}
\hline Instrument & Uncertainty \\
\hline K-type thermocouples & $\pm 1.27 \circ \mathrm{C}$ \\
Flowmeter & $\pm 0,0000015 \mathrm{~m}^{3} / \mathrm{s}$ \\
Power supply & $\pm 3 \mathrm{mV}$ \\
Power supply & $\pm 3 \mathrm{~mA}$ \\
\hline
\end{tabular}

\section{Results}

Figures 4 to 6 present the temperature distribution for each thermosyphon versus time for a water flow rate of $0.50 \mathrm{~L} / \mathrm{min}$.

Comparing Figures 4 to 6 , it can be seen that all thermosyphons presented the same behavior. Temperatures start to rise when the heat load is applied and then stabilize when the steady state is reached. Besides that, the evaporator presented higher temperatures than the adiabatic section, which presented higher temperatures than the condenser.

Temperature peaks at the $35 \mathrm{~W}$ heat load can be explained by the fact that at first, when the process of evaporation and condensation has not started yet, the lower region of the evaporator has a higher mass to be heated than the rest of the thermosyphon, since it's the region that contains the working fluid. Therefore, this region presents lower temperatures than the others, stabilizing when the cycle of evaporation and condensation starts.

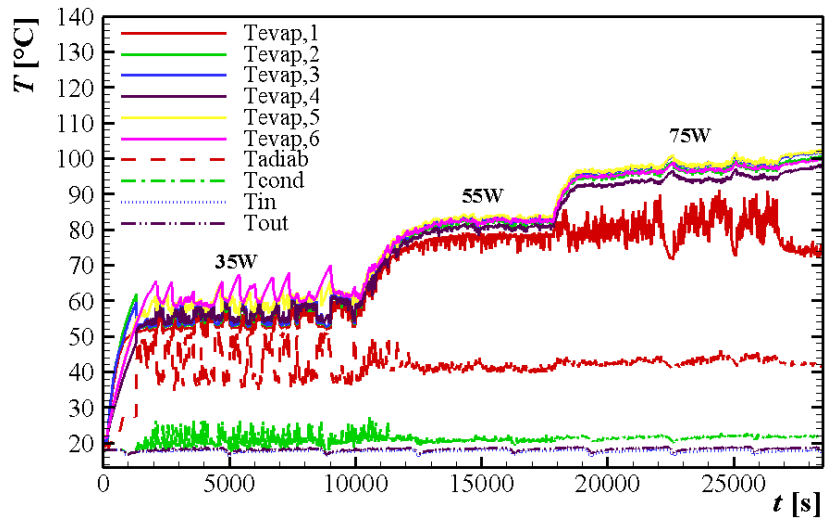

Figure 4 . Temperature distribution for $5 \%$ graphene oxide nanofluid and $0.50 \mathrm{~L} / \mathrm{min}$

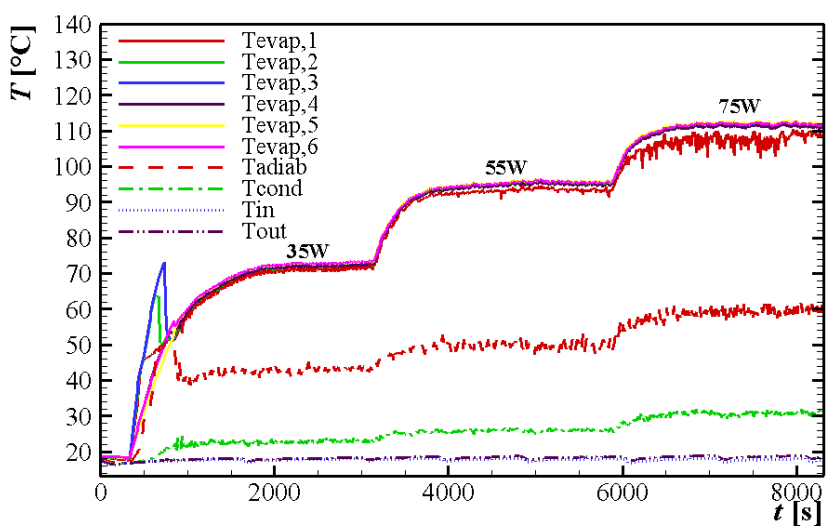

Figure 5. Temperature distribution for $10 \%$ graphene oxide nanofluid and $0.50 \mathrm{~L} / \mathrm{min}$

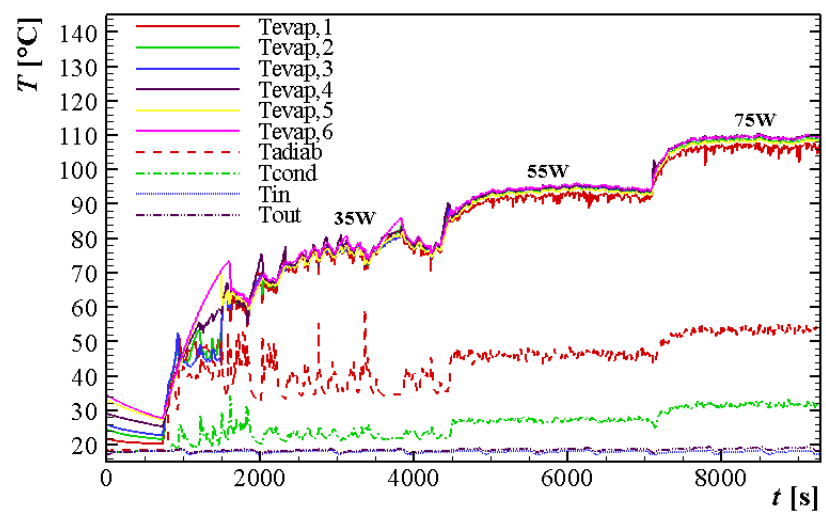

Figure 6. Temperature distribution for

distilled water and $0.50 \mathrm{~L} / \mathrm{min}$

Figures 7 to 9 present the temperature distribution for each thermosyphon versus time for a water flow rate of $0.75 \mathrm{~L} / \mathrm{min}$.

Comparing Figures 4 to 6 and Figures 7 to 9 , it is noticeable that a higher flow rate tends to result in lower temperatures for each heat load and each section of the devices. $5 \%$ graphene oxide still presented the lowest temperature values out of the three fluids. 


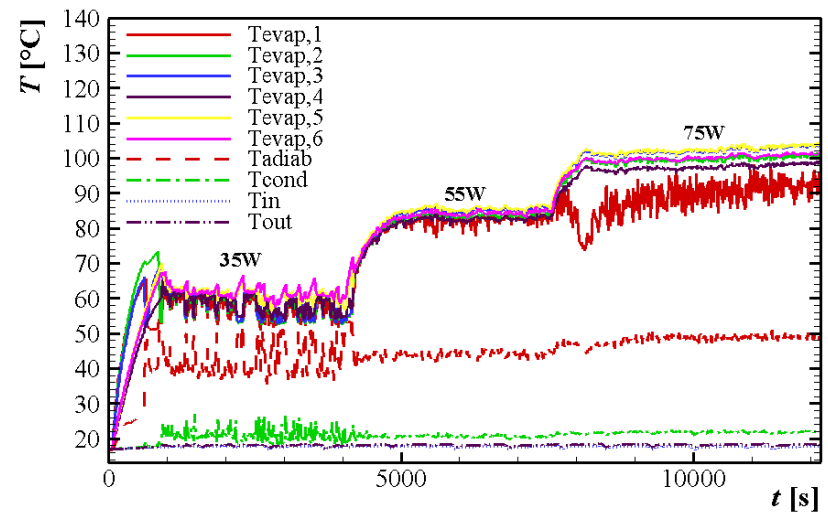

Figure 7. Temperature distribution for $5 \%$ graphene oxide nanofluid and $0.75 \mathrm{~L} / \mathrm{min}$

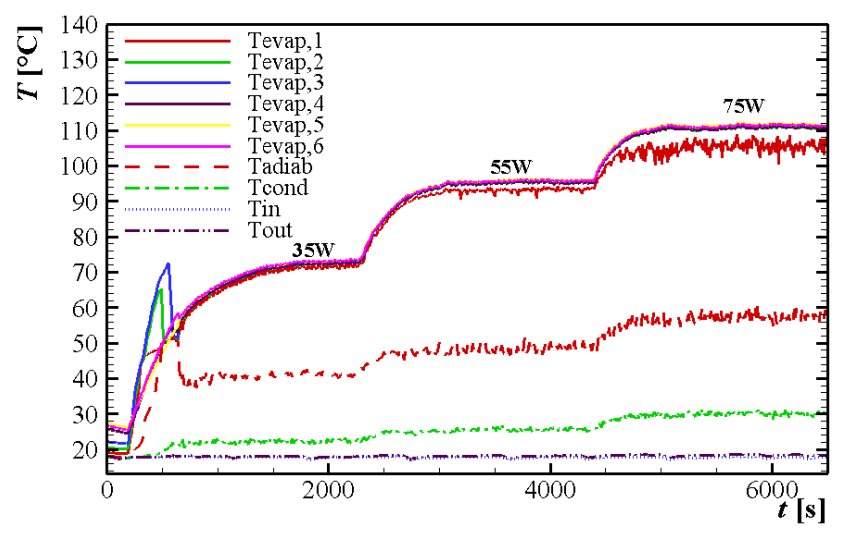

Figure 8. Temperature distribution for $10 \%$ graphene oxide nanofluid and $0.75 \mathrm{~L} / \mathrm{min}$

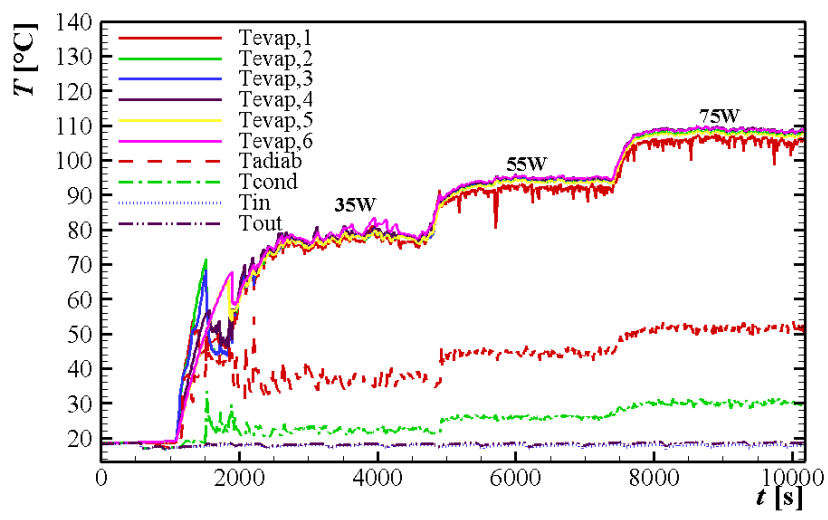

Figure 9. Temperature distribution for

distilled water and

$$
0.75 \mathrm{~L} / \mathrm{min}
$$

Figures 10 to 12 present the temperature distribution for each thermosyphon versus time for a water flow rate of $1.00 \mathrm{~L} / \mathrm{min}$.

Again it is noticeable that, in general, increasing the flow rate resulted in lower temperatures, mostly due to the flow rate and flow velocity influence on the convection coefficient, since higher flow velocities, keeping all the other parameters constant, tend to increase the coefficient and also the heat exchange.

From all the temperature distribution results it is also verified that $10 \%$ graphene oxide nanofluid presented, in general, the higher temperatures for each heat load, flow rate and section of the thermosyphon.

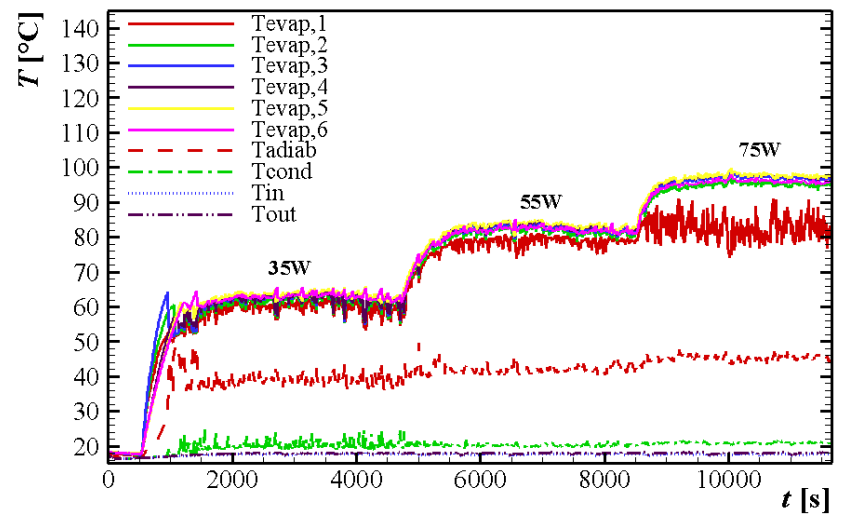

Figure 10. Temperature distribution for $5 \%$ graphene oxide nanofluid and $1.00 \mathrm{~L} / \mathrm{min}$

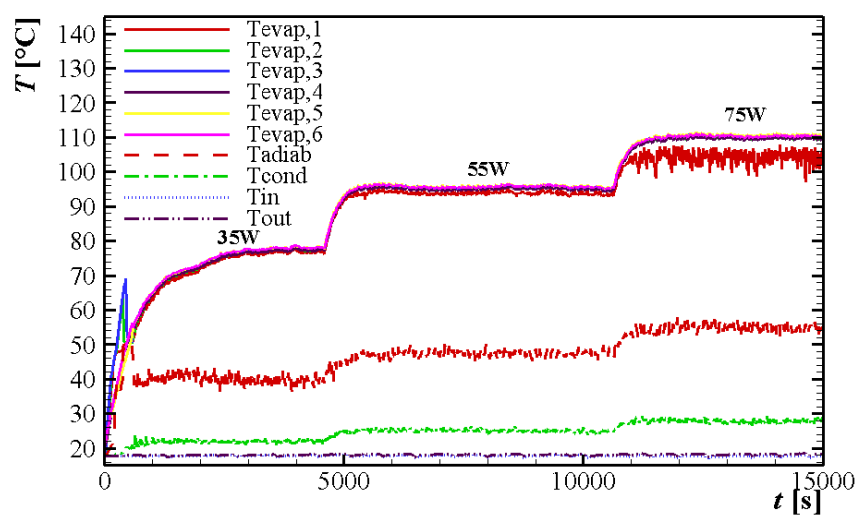

Figure 11. Temperature distribution for $10 \%$ graphene oxide nanofluid and $1.00 \mathrm{~L} / \mathrm{min}$

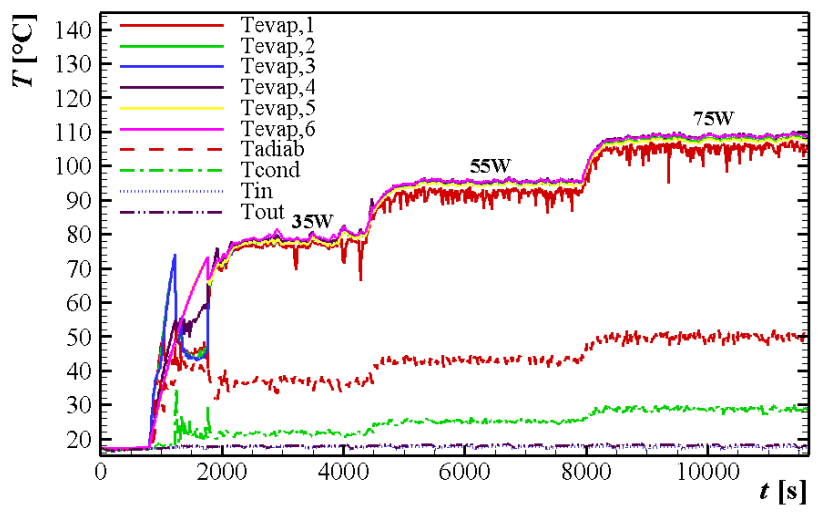

Figure 12. Temperature distribution for distilled water and

$$
1.00 \mathrm{~L} / \mathrm{min}
$$

Thermal resistance data presented at Figures 13 to 15 indicate that all the three thermosyphons were operating correctly, since in general the thermal resistance values showed a tendency to decrease with increasing heat load and, from Equation (1), the thermal resistance is inversely proportional to the value of the applied heat load.

It can be seen that for all the flow rates analyzed, the thermosyphon that uses $5 \%$ graphene oxide has the lowest thermal resistance values, whereas the thermosyphons filled with distilled water and $10 \%$ graphene oxide have very similar thermal resistance values when taking into account the spread of measurement uncertainties. 


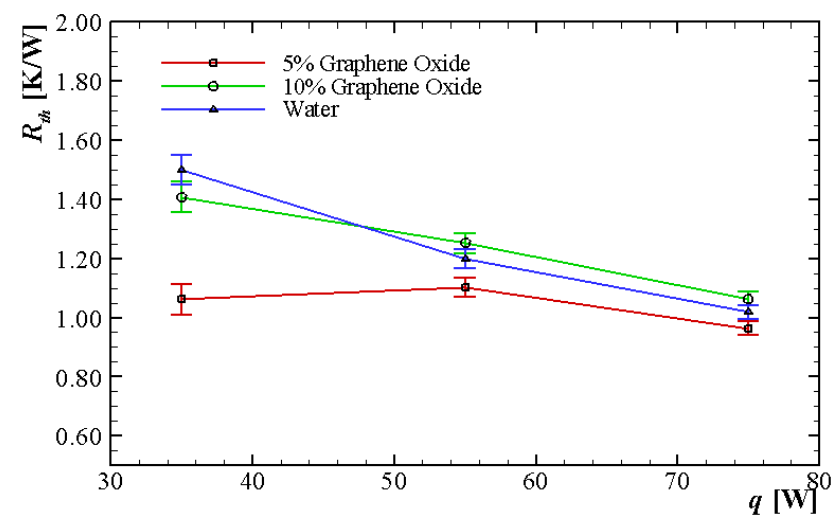

Figure 13. Thermal resistance for $0.50 \mathrm{~L} / \mathrm{min}$

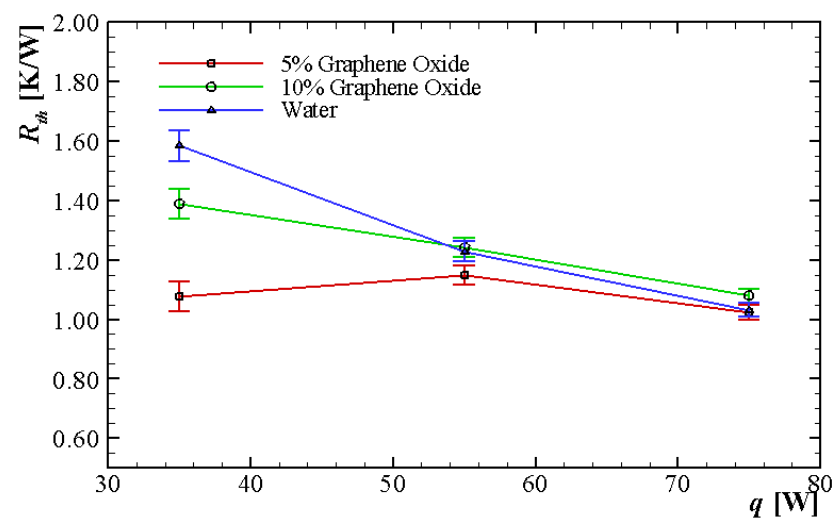

Figure 14. Thermal resistance for $0.75 \mathrm{~L} / \mathrm{min}$

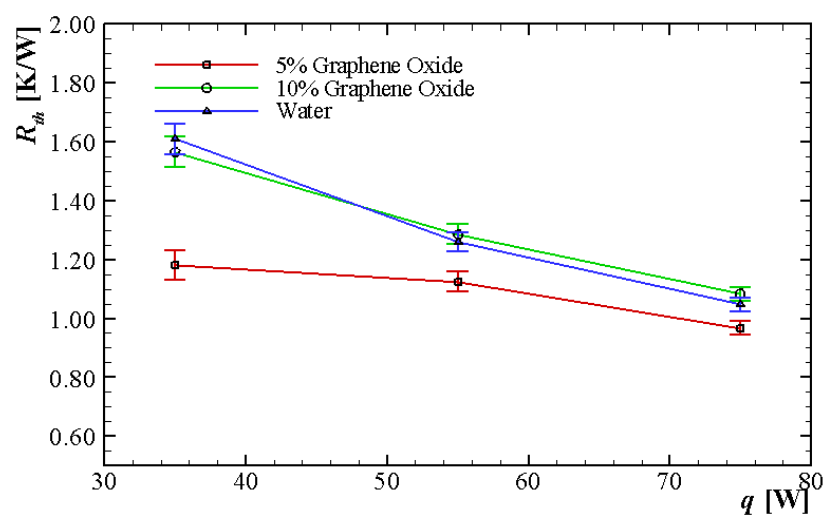

Figure 15. Thermal resistance for $1.00 \mathrm{~L} / \mathrm{min}$

The lowest thermal resistance value obtained was $0.964 \mathrm{~K} / \mathrm{W}$ for the thermosyphon filled with $5 \%$ graphene oxide at a thermal load of $75 \mathrm{~W}$ and water flow rate of $0.50 \mathrm{~L} / \mathrm{min}$. Considering these facts, the working fluid indicated for the desired destination (filling of thermosyphons for application in solar collectors of high pressure vacuum tubes) is the $5 \%$ graphene oxide.

\section{Conclusions}

In this study, the thermal analysis of three thermosyphons was described in detail. The proposed procedure has a low cost and the passive heat transfer devices are easy to manufacture, being built based on thermosyphons present in commercial high pressure vacuum tube solar collectors. With that done, an experimental investigation of the thermal performance of three thermosyphons with different working fluids (distilled water and 5\% and 10\% graphene oxide nanofluids) and three different volumetric water flows $(0.50,0.75$, and $1.00 \mathrm{~L} / \mathrm{min})$ was performed. Passive heat transfer devices were tested in the $25^{\circ}$ horizontal position under thermal loads of 35,55 , and $75 \mathrm{~W}$, all working satisfactorily.

The thermal analysis was based on the temperature distribution of the thermosyphons as a function of time, and thermal resistance as a function of the applied thermal load. In general, with the increase in the water flow rate under the condenser, a reduction in temperature was observed in all regions of the thermosyphons. The device containing $5 \%$ graphene oxide nanofluid as working fluid showed the lowest temperature values for all flow rates tested and also thermal resistance for all thermal loads applied. Thus, it was identified that, for the conditions tested, the working fluid composed of $5 \%$ graphene oxide nanofluid presented itself as the best passive thermal exchange device option to be applied in a high vacuum tube solar collector pressure between all the devices analyzed.

\section{Nomenclature}

$q:$ heat transfer rate [W]

$R_{t h}:$ total thermal resistance $\left[{ }^{\circ} \mathrm{C} / \mathrm{W}\right]$

$T_{\text {cond }}:$ condenser temperature $\left[{ }^{\circ} \mathrm{C}\right]$

$T_{\text {evap }}$ : evaporator temperature $\left[{ }^{\circ} \mathrm{C}\right]$

\section{Declaration of Conflict of Interests}

The authors declare that there is no conflict of interest. They have no known competing financial interests or personal relationships that could have appeared to influence the work reported in this paper.

\section{References}

[1.] Kabir, E., Kumar, P., Kumar, S., Adelodun, A.A., Kim, K.H., Solar energy: potential and future prospects. Renewable and Sustainable Energy Reviews, 82 (2018) 894-900.

[2.] Sumathi, S., Ashok, L.K., Surekha, P., Solar PV and wind energy conversion systems: an introduction to theory, modeling with MATLAB/ SIMULINK, and the role of soft computing techniques. Springer 2 (2015) 59-143.

[3.] Abo-Elfadl, S., Hassan, H., Eldosoky, M.F., Energy and exergy assessment of integrating reflectors on thermal energy storage of evacuated tube solar collector-heat pipe system. Solar Energy 209 (2020) 470-484.

[4.] Santos, P.H.D., Vicente, K.A.T., Reis, L.S., Marquardt, L.S., Antonini Alves, T., Modeling and experimental tests of a copper thermosyphon. Acta Scientiarum. Technology (Online) 39 (2017) 59-68.

[5.] Reay, D.A., Kew, P.A., McGlen, R.J., Heat Pipes: Theory, Design and Applications. 6ed. Waltham, MA, USA: Elsevier (2014).

[6.] Krambeck, L., Nishida, F.B., Aguiar, V.M., Santos, P.H.D., Antonini Alves, T. Thermal performance evaluation of different passive devices for electronics cooling. Thermal Science 23 (2019) 11511160 .

[7.] Krambeck, L., Bartmeyer, G.A., Souza, D.O., Fusão, D., Santos, P.H.D., Antonini Alves, T., Experimental thermal performance of different capillary structures for heat pipes. Energy Engineering (Print) 118 (2021) 1-14.

[8.] Krambeck, L., Bartmeyer, G.A., Fusão, D., Santos, P.H.D., Antonini Alves, T.,Experimental research of capillary structure technologies for heat pipes. Acta Scientiarum. Technology (Online) 42 (2020) e48189.

[9.] Mantelli, M.B.H., Thermosyphon Technology for Industrial Applications. (Chapter 11) In: Vasiliev, L.L., Kakaç, S. (Eds.). Heat pipes and solid sorption transformations: fundamentals and practical applications. Boca Raton: CRC Press (2013).

[10.] Ersoz, M.A., Effects of different working fluid use on the energy and exergy performance for evacuated tube solar collector with thermosyphon heat pipe. Renewable Energy 96 (2016) 244-256.

[11.] Santos, P.H.D., Krambeck, L., Santos, D.L.F., Antonini Alves, T., Analysis of a stainless steel heat pipe based on operation limits. International Review of Mechanical Engineering (Testo Stampato) 8 (2014) 599-608. 
[12.] Fallahazadeh, R., Aref, L., Gholamiarjenaki, N., Nonejad, Z., Saghi, M., Experimental investigation of the effect of using water and ethanol as working fluid on the performance of pyramid-shaped solar still integrated with heat pipe solar collector. Solar Energy 207 (2020) 10-21.

[13.] Dehaj, M.S., Mohiabadi, M.Z., Experimental investigation of hea pipe solar collector using MgO nanofluids. Solar Energy Materials and Solar Cells 191 (2019) 91-99.

[14.] Eltaweel, M., Abdel-Rehim, A.A., Attia, A.A.A., Energetic and exergetic analysis of a heat pipe evacuated tube solar collector using MWCNT/water nanofluid. Case Studies in Thermal Engineering 22 (2020) 100743.

[15.] Hummers, W.S., Offeman, R.E., Preparation of Graphitic Oxide. Journal of the American Chemical Society 80 (1958) 1339.

[16.] Murray, R., Graphene 101 an inventor's, guide to making graphene. United States of America: Smashwords Edition (2013).

\section{How to Cite This Article}

Machado, P.L.O., Bartmeyer, G.A., Dimbarre, V.V., Souza, R.O., Lenart, V.M., Gomez, R.F.T., Santos, P.H.D., Antonini Alves, T., Thermal Performance of Thermosyphons intended for Evacuated Tube Solar Collector using Graphene Oxide Nanofluids, Journal of Nature, Science \& Technology, 1 (2021), 14-19.

https://doi.org/10.36937/janset.2021.001.003
[17.] Antonini Alves, T., Krambeck, L., Santos, P.H.D., Heat Pipe and Thermosyphon for Thermal Management of Thermoelectric Cooling, (Chapter 17). In: Aranguren, P. (Org.). Bringing Thermoelectricity into Reality. 1. ed. London: InTechopen (2018). [18.] Bartmeyer, G. A., Machado, P. L. O., Dimbarre, V. V., Alves, T. A. Influence of Working Fluid on Thermal Performance of Thermosyphons Intended for Applications in High Pressure Vacuum Tube Solar Collectors. In: 18th Brazilian Congress of Thermal Sciences and Engineering - ENCIT, 2020, Online.

[19.] Holman, J.P., Experimental Methods for Engineers, 6.ed., Singapure, Mcgrall-Hill (1994).

[20.] Kline, S.J., McClintock, F.A., Analysis of uncertainty in singlesample experiments. Mechanical Engineering 75 (1953) 3-9. 